\title{
Exploring new drilling prospects in the southwest Pacific
}

\author{
S. J. Gallagher ${ }^{1}$, N. Exon ${ }^{2}$, M. Seton ${ }^{3}$, M. Ikehara ${ }^{4}$, C. J. Hollis ${ }^{5}$, R. Arculus ${ }^{2}$, S. D'Hondt ${ }^{6}$, C. Foster ${ }^{7}$, \\ M. Gurnis ${ }^{8}$, J. P. Kennett ${ }^{9}$, R. McKay ${ }^{10}$, A. Malakoff ${ }^{5,}$, J. Mori ${ }^{11}$, K. Takai ${ }^{12}$, and L. Wallace ${ }^{13}$ \\ ${ }^{1}$ The School of Earth Sciences, The University of Melbourne, Victoria 3010, Australia \\ ${ }^{2}$ Research School of Earth Sciences, Australian National University, Canberra 0200, Australia \\ ${ }^{3}$ Earthbyte Group, School of Geosciences, University of Sydney, NSW 2006, Australia \\ ${ }^{4}$ Center for Advanced Marine Core Research, Kochi University, Nankoku 783-8502, Japan \\ ${ }^{5}$ GNS Science, Lower Hutt 5040, New Zealand \\ ${ }^{6}$ Graduate School of Oceanography, University of Rhode Island, Narragansett, RI 02882, USA \\ ${ }^{7}$ Geoscience Australia, Canberra, ACT 2601, Australia \\ ${ }^{8}$ California Institute of Technology, Pasadena, CA 91125, USA \\ ${ }^{9}$ Department of Earth Sciences, University of California, Santa Barbara CA 93106, USA \\ ${ }^{10}$ Antarctic Research Centre, Victoria University of Wellington, Wellington 6140, New Zealand \\ ${ }^{11}$ Earthquake Hazards Division, Kyoto University Kyoto 611-0011, Japan \\ ${ }^{12}$ Subsurface Geobiology Advanced Research (SUGAR) Project, Japan Agency for Marine-Earth Science \& \\ Technology (JAMSTEC), 2-15 Natsushima-cho, Yokosuka 237-0061, Japan \\ ${ }^{13}$ Jackson School of Geosciences, The University of Texas at Austin, TX 78713, USA \\ *retired \\ Correspondence to: S. J. Gallagher (sjgall@unimelb.edu.au)
}

Received: 30 July 2013 - Revised: 1 November 2013 - Accepted: 18 November 2013 - Published: 29 April 2014

\begin{abstract}
A major International Ocean Discovery Program (IODP) workshop covering scientific ocean drilling in the southwest Pacific Ocean was held in Sydney, Australia, in late 2012. The workshop covered all fields of geoscience, and drilling targets in the area from the Equator to Antarctica. High-quality contributions and a positive and cooperative atmosphere ensured its success. The four science themes of the new IODP science plan were addressed. An additional resource-oriented theme considered possible co-investment opportunities involving IODP vessels. As a result of the workshop, existing proposals were revised and new ones written for the April 2013 deadline. Many of the proposals are broad and multidisciplinary in nature, hence broadening the scientific knowledge that can be produced by using the IODP infrastructure. This report briefly outlines the workshop and the related drilling plans.
\end{abstract}

1

\section{Introduction}

The southwest Pacific is one of the most tectonically active regions on Earth, associated with large earthquake and volcanic events occurring on human time scales. The tectonics of this region are largely driven by deep earth processes that cause flows of material and energy among global reservoirs that affect major changes in Earth structure and composition. The area is also an important driver of global climate change and constitutes a key element of global thermohaline circulation. Future drilling of the sedimentary archives in the re- gion will continue to yield vital information about the relative roles of ocean heat transport and greenhouse gas forcing on the warming and cooling of our planet, ice sheet stability and pole to equator climatic teleconnections. Drilling large igneous provinces will enhance our knowledge of the potential role of deep earth processes on the development of Earth's crust and atmosphere, and potential relationship with mass extinctions. Sampling plate boundary archives will increase our understanding of subduction initiation, earthquake and volcanic eruption frequency and volcanic arc formation. Installing borehole observatories at plate boundaries will allow 
Table 1. List of proposals in the southwest Pacific region. Note: NR $=$ riserless, $\mathrm{R}=$ riser and $\mathrm{MSP}=$ mission-specific platform drilling proposals.

\begin{tabular}{lllll}
\hline Proposal & Title & PI & Country & Platform \\
\hline 567-Full4 & South Pacific Palaeogene & Thomas & USA & NR \\
730-Pre2* & Sabine Bank Sea Level & Taylor & USA & MSP \\
751-Full & West Antarctic Ice Sheet Climate & Bart & UK & NR \\
781-MDP & Hikurangi Subduction Margin & Wallace & USA/NZ & R+NR \\
781A-Full & Hikurangi Observatory & Saffer & USA & NR \\
781B-Full & Hikurangi Riser & Wallace & USA/NZ & R \\
799-Full* & Western Pacific Warm Pool & Rosenthal & USA & NR \\
813-Pre & Antarctic Margin & Williams & USA & NR \\
818-Pre & Brothers Arc Flux & de Ronde & NZ & NR \\
831-APL & Campbell Drift Climate & Turner & USA & NR \\
832-Full & Tasman Frontier Subduction & Sutherland & NZ & NR \\
\hline
\end{tabular}

${ }^{*}$ Not discussed in this report.

megathrust slip processes and earthquake intensity to be investigated on human timescales. Drilling oceanic crust will reveal the nature of poorly known microbial communities and their potential role in processes related to the alteration of igneous crust, sedimentary diagenesis, hydrocarbon and mineral deposit formation and destruction. These processes will help reveal effects of microbes on subduction zone geochemistry, and potential influences of microbes on paleaoceanographic records. This region has also significant economic potential for mineral and petroleum resources. Collaboration among regional geological survey organisations and industry with the IODP through complementary drilling proposals will likely yield insights into deep and shallow earth processes.

\section{Workshop goals}

The southwest Pacific IODP workshop was hosted by Sydney University, Australia, in October 2012. An international group of eighty scientists reviewed the latest research about the region, discussed major questions that should be addressed with future deep ocean drilling through the International Ocean Discovery Program (IODP), and set up working groups to develop new drilling proposals in the region. The workshop covered all science themes of the new IODP science plan for 2013-2023 and an additional theme focusing on marine resource opportunities. A list of the current IODP proposals in the region is in Table 1.

\subsection{Theme 1 - climate and ocean change: reading the past, informing the future}

We recognise a major need for depth and latitudinal transects of sediment cores in the southwest (SW) Pacific, including the Pacific sector of the Antarctic margin, using a variety of ship-based and floating ice-based platforms, to address fundamental questions about past global change. This drilling will take advantage of the unusual opportunity that southwest Pacific topography offers for obtaining meridional core transects at relatively shallow water depths from the tropics to the polar region. This includes the Lord Howe Rise, which was identified as a special target for obtaining a north-south transect in the proposed SW Pacific drilling. The research expeditions proposed by April 2013 (Fig. 1) will investigate the relative roles of ocean heat transport and greenhouse gas forcing in the warming and cooling of Earth's climate, ice sheet stability and non-linear climate feedbacks, and pole to equator teleconnections. The work will also help to resolve current discrepancies existing between climate proxies and climate models.

\subsubsection{Palaeogene transect: tropics to Antarctica}

The proposals in this subtheme share the common purpose of better understanding major shifts in temperature and other paleoenvironmental gradients between the tropics and the Southern Ocean during the greenhouse world of the early Palaeogene. The expeditions will test hypotheses posited to better understand the now well-known extreme warmth at high latitudes during the early Palaeogene; the origin and development of the Southern Ocean and its role in driving global climate change; and the nature of major late Palaeogene cooling and growth of the Antarctic Ice Sheets during the Eocene-Oligocene transition (32 Ma).

\subsubsection{7-Full4: Palaeogene South Pacific latitude transect}

This expedition has been proposed to investigate the subpolar Pacific climate, oceanographic structure, and biogeochemical cycling of the remarkably warm Eocene through the transition to icehouse conditions in the Oligocene during the development of major continent-wide Antarctic ice sheets. 


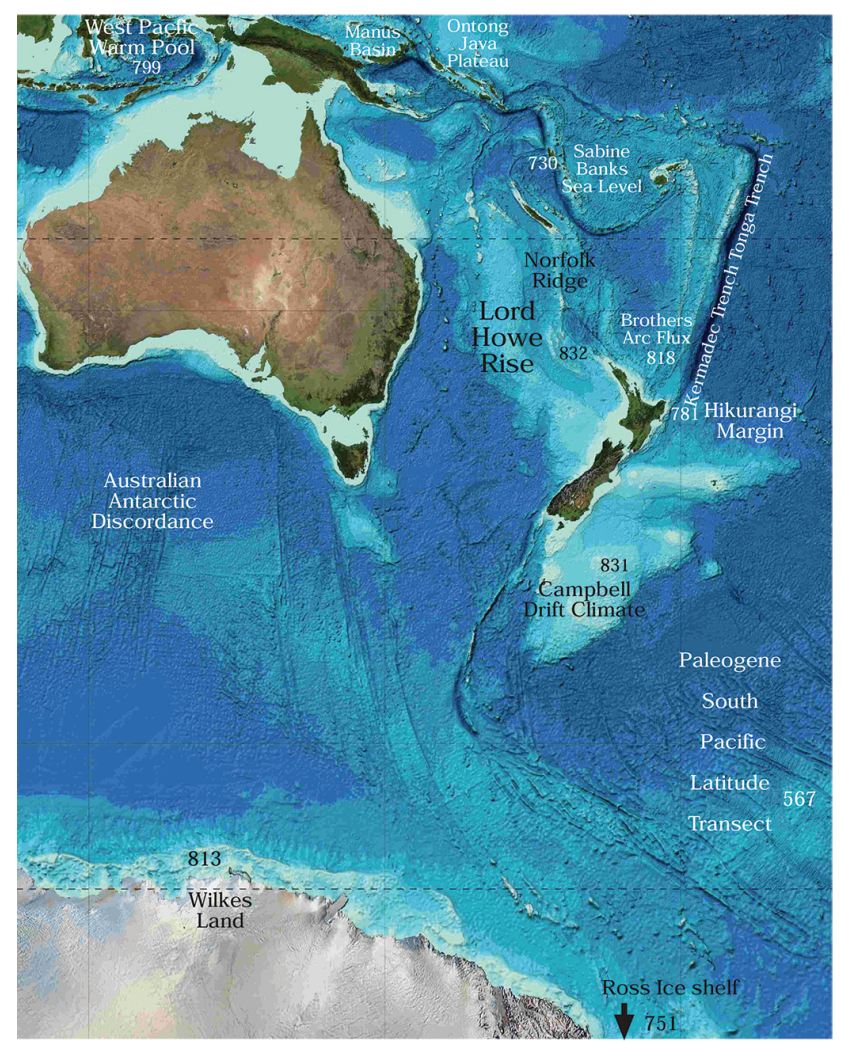

Figure 1. Location of existing drilling proposals in the southwest Pacific region. Base map adapted from General Bathymetric Chart of the Oceans (GEBCO) www.gebco.net. Proposals 730 and 799 are not discussed in this report.

\subsubsection{3-Pre: Antarctic Cenozoic palaeoclimate (George V Land and Adélie Land shelves)}

A proposal has been formulated for the use of seabed drilling in the recovery of two stratigraphic transects of shallow $(\sim 50 \mathrm{~m})$ sites. The proximal sites are expected to yield more continuous Palaeogene and Neogene records than was possible during IODP 318 and provide further insight into Antarctica's climate evolution and its role in driving global climate change in the past.

\subsubsection{1-APL: Campbell Drift climate (western Campbell Plateau and Campbell Drift)}

Two regions on the Campbell Plateau are identified as having significant potential for paleoceanographic advances with possibilities of a single expedition or two linked expeditions to investigate the evolution of Cretaceous-Palaeogene climate and ocean circulation at high southern palaeolatitudes. Drilling would also use modern drilling technology at important sites drilled in earlier ocean drilling expeditions (e.g. DSDP (Deep Sea Drilling Program) site 277 and IODP site 1121).

\subsubsection{Neogene and Quaternary climate and ocean change}

The Neogene and Quaternary experienced the permanent development of the East Antarctic Ice Sheet during the midMiocene, and the full expansion of Southern Ocean sea ice by the mid-Pleistocene. Proposals will address major expansion of the West Antarctic ice sheet during the late Miocene, the history of West Antarctic Ice Sheet variability on the outer Ross Sea continental shelf and related oceanographic changes on the adjacent continental slope (751-Full), and the history of the East Antarctic Ice Sheet on the Wilkes Land continental shelf (813-Pre: summarised above).

\subsection{Theme 2 - biosphere frontiers: deep life, biodiversity, and environmental forcing of ecosystems}

The diverse geologic environments of the southwest Pacific and neighbouring oceanic regions provide numerous ideal opportunities to investigate many aspects of challenges related to a better understanding of the deep biosphere. Taking fullest advantage of these opportunities will require three different project strategies. A minimal strategy would be to have microbiologists, biogeochemists and other appropriate specialists participate in expeditions planned with other primary objectives. This strategy will typically involve shipboard and post-expedition microbiological and biogeochemical study of cores and logs collected for other purposes. Other projects will require the more dedicated strategy inherent in IODP ancillary project letters, which add relatively minimal additional drilling time to scheduled expeditions. Finally, some objectives would be best met with large-scale expeditions fully dedicated to drilling.

\subsubsection{Subseafloor microbes and the world}

Topics needing special attention include the influence of subseafloor microbes on Earth and ocean history, the influence of subseafloor microbes on local and global cycling of carbon, nitrogen, phosphorus, sulfur and a host of other elements. More specific topics include (i) the role of microbes in many different processes, including alteration of igneous crust, diagenesis of marine sediment, formation and destruction of metalliferous deposits, formation and destruction of hydrocarbon deposits, (ii) the effect of microbes on the geochemistry of the subduction factory, and (iii) the influence of microbes on paleoceanographic records.

Drilling projects in the southwest Pacific will provide special opportunities to address most of these topics. Drilling in the Gulf of Papua provides one such opportunity, allowing for the close study of temporal variation and microbial influence in source-to-sink carbon cycling on a continental margin. It will also provide an excellent opportunity for examining the sensitivity of subseafloor ecosystems and biodiversity to glacial-interglacial change in sea level and tropical 
sedimentation. Another example is drilling in the Great Australian Bight, which will allow close examination of sulfurcycling microbial communities in a large-scale subseafloor reflux-brine system (Wortmann et al., 2011). A third example is provided by southwestern Pacific subduction regions, including the Hikurangi Subduction Margin and the Tonga Trench, where the influence of subseafloor microbes on the geochemistry of the subduction factory can be examined.

\subsection{Theme 3 - Earth connections: deep processes and their impact on Earth's surface environment}

The southwest Pacific is one of the most active areas of the world in terms of the connections between deep processes and their impact on Earth's surface. Flows of material and energy among global reservoirs drive long-term changes in Earth's structure and composition, cause volcanism and tectonism, and create hospitable environments for the development and evolution of life. Plate tectonic processes have been eclipsed at times in Earth's history by episodes of massive magmatic outpourings in small areas, events that may occur when hot mantle ascends rapidly from great depth to erupt on Earth's surface, forming oceanic plateaus and continental flood basalts (so-called large igneous provinces, or LIPs). Within the southwest Pacific, the largest such LIP occurs with the Ontong Java Plateau (OJP, Fig. 2). The causes and environmental consequences of catastrophic magmatism forming large igneous provinces remain poorly constrained. Likewise, the processes that initiate new plate boundaries, a first-order problem in Earth dynamics, are poorly understood. At convergent plate boundaries, the initiation of subduction and formation of volcanic arcs remain enigmatic. The SW Pacific has a greater range of well-preserved subduction initiation events than anywhere else on Earth.

\subsubsection{Formation of large igneous provinces and their impact on the global environment}

The Ontong Java Plateau (Fig. 2) is the world's largest oceanic plateau and the most voluminous large igneous province on Earth. The implication is that the Greater Ontong Java Plateau volcanic event covered $\sim 1 \%$ of Earth's surface. The similar basalt chemistry and ages of eruptive episodes recorded by these constructs suggest a unique magmatic event in the history of Earth. Such a huge outpouring of lava during the initial constructional phase of the Greater Ontong Java Plateau is synchronous with the oceanic anoxic "Selli" event, suggesting a significant impact on ocean chemistry (Tejada et al., 2009). Large igneous province science would be advanced in five key areas through scientific ocean drilling: Obtaining deep sections within multiple large igneous provinces to examine magmatic (and therefore mantle source) variability through time; defining the nature of melting anomalies (which produce large igneous provinces); defining precise durations of oceanic large igneous province

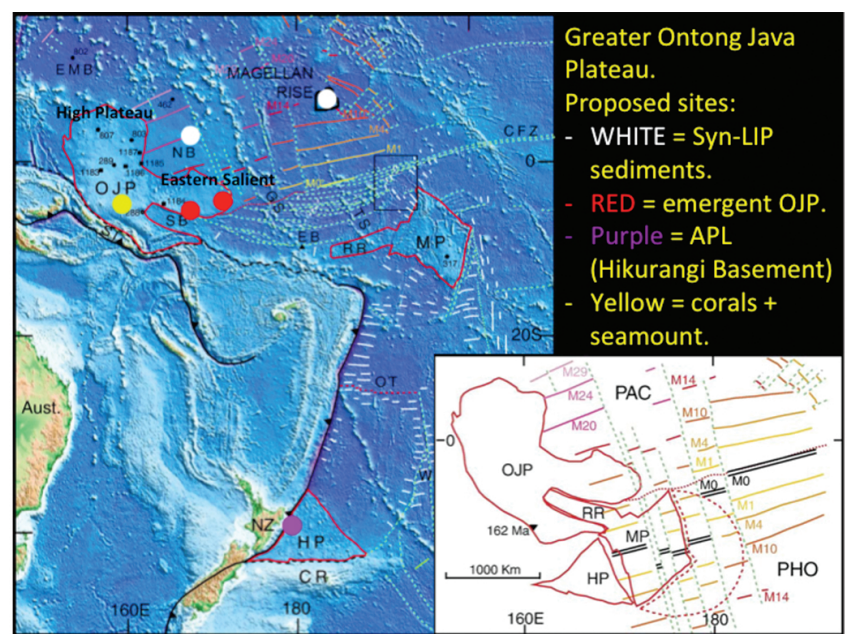

Figure 2. Present configuration of large igneous provinces (LIPs) in the SW Pacific (outlined in red) with proposed drilling sites. The inset shows reconfiguration of the Greater Ontong Java Plateau (OJP) suggesting the Ontong Java and Hikurangi (HP) plateaus and the Manihiki Plateau (MP) all formed during a single event adapted from Taylor (2006). Note: Robbie Ridge (RR), Ellis Basin (EB), East Mariana Basin (EMB), Nauru Basin (NB), Clipperton Fracture Zone (CFZ), Osbourn Trough (OT) and Chatham Rise (CR) are also shown. The inset shows a reconstruction at $\sim 125 \mathrm{Ma}$ prior to breakup and before Pacific (PAC) - Phoenix (PHO) spreading (from Taylor, 2006).

events; defining modes of eruption-constant effusion over several million years or several large pulse events over the same time interval; establishing relationships among oceanic large igneous provinces, oceanic anoxic events (OAEs), and other major environmental changes.

\subsubsection{Structure and dynamics of mantle flow}

Workshop participants discussed the scientific opportunities for further study of the Australian-Antarctic Discordance (AAD), as the region presents us with unique opportunities to address the IODP challenges concerning the composition, structure, and dynamics of Earth's upper mantle.

\subsubsection{Initiation of subduction and origin of deep-water sedimentary basins}

Subduction systems are the primary drivers of plate motions, mantle dynamics, and global geochemical cycles, but little is known about how subduction starts. What are the necessary initial conditions? How do forces and kinematics evolve? What are the short-term lithospheric consequences and surface signatures: vertical movements, deep-water sedimentary basins, convergence, extension, and volcanism? The southwest Pacific also provides an ideal opportunity to understand the process of large-scale subduction initiation because the Eocene onset of new subduction zones was accompanied by 
the most profound global reorganisation of tectonic plates since the late Cretaceous, and within the only part of Earth history with precisely known plate motions (Gurnis et al., 2004; Steinberger et al., 2004).

\subsubsection{Full: the Lord Howe Rise}

The "Tasman frontier" is a sector of the southwest Pacific that lies between eastern Australia, western New Zealand, and New Caledonia (Fig. 1). Future ocean drilling in the Tasman Frontier (TF) is intriguing, because sedimentary records could address and several major challenges that relate to different themes, such as: how and why does subduction initiation occur? Did plate convergence precede and induce subduction initiation, or did it happen spontaneously? What vertical stresses occurred during subduction initiation? The magnitude and timing of uplift and subsidence across a broad region could be determined through drilling specific targets, ones that will enable evaluation and refinement of geodynamic models. Far-field uplift and subsidence, as strongly indicated from seismic stratigraphy, challenges existing geodynamic theory. Was regional bathymetry during the Palaeogene much different than it is at present? Proposed sites would target horizons that, from available seismic stratigraphy, suggest much of the Tasman Frontier was at or near sea level in the early Eocene, which would impact climate model simulations significantly. Did subduction initiation coincide with early Eocene warmth? How and why do Neogene oceanographic changes in the region relate to those elsewhere?

\subsection{Theme 4 - Earth in motion: processes and hazards on human time scales}

The southwest Pacific is one of the most active regions in the world in terms of the earthquake and volcanic events that frequently occur on human time scales. High-magnitude earthquakes and large volcanic eruptions reoccur at intervals of decades to centuries. Also other smaller events, such as slowslip events and moderate eruptions, have even shorter repeat intervals that can be observed within a scientist's career. The sites of these events are prime targets for the ocean drilling program, where logging, coring and installing observatories in boreholes can be used to better understand dynamic processes such as the seismic and aseismic slip on megathrusts, the magmatic system under volcanoes, and the triggering of large landslides.

\subsubsection{Hikurangi subduction margin IODP proposals to understand the origin of slow-slip event behaviour}

Over the last decade, the discovery of episodic slow-slip events (SSEs) at subduction margins around the globe has led to an explosion of new theories about fault mechanics and subduction interface deformation mechanisms and rheology.
The Hikurangi margin is the subject of three existing IODP proposals to "unlock the secrets of slow slip": 781-MDP (Multi-phase drilling project), 781A-Full (riserless drilling transect and observatories), and 781B-Full (riser drilling to intersect the slow-slip source area). The riser drilling proposal was a major topic of discussion at the workshop, and it was recently submitted to IODP in April 2013; the riserless proposal (781A-Full) has been forwarded by PEP to the JR facilities board with an excellent rating, and is awaiting ranking and scheduling. In addition to studies of slow slip, a number of other new ideas for using IODP drilling at the Hikurangi margin to understand gas hydrates and submarine landsliding processes were also developed and discussed at the workshop. We anticipate that some of these new ideas will be submitted either as APLs (Ancillary Project Letters) or full proposals in the future.

\subsubsection{Global comparison of slip behaviour at the toe of subduction margin trenches}

In the 2011 Tohoku $M_{\mathrm{w}} 9.0$ earthquake, the largest slip $(>50 \mathrm{~m}$ ) occurred on the shallowest portion of the subduction thrust (Ito et al., 2011; Kodaira et al., 2012), which contributed greatly to the huge tsunami that followed the earthquake (Maeda et al., 2011). At the Nankai Trough, vitrinite reflectance studies of IODP cores from the shallow fault zone $(<500 \mathrm{~m})$ suggest frictional heating and large, seismic slip close to the trench in previous megathrust earthquakes at Nankai (Sakaguchi et al., 2011). These new observations beg the question: do subduction megathrusts elsewhere commonly undergo large, seismic slip all the way to the trench? This is in stark contrast to the traditional view that the shallow megathrust is largely aseismic. A comparative study of shallow cores through the toe of many of the world's active subduction thrusts, including those in the southwest Pacific region such as the Hikurangi and Kermadec margins, is needed and would give us an excellent start in trying to gain a more comprehensive understanding of shallow megathrust seismic behaviour.

\subsection{Theme 5 - marine resources: opportunities and responsibilities}

The aim of this theme was to determine the contribution that IODP could make to the exploration, characterisation and responsible exploitation of marine resources in the southwest Pacific region. These resources might include offshore oil and gas, gas hydrates, and offshore minerals. There are additional opportunities to draw economic benefits from IODP participation: incorporating "marine resource" considerations into standard scientific proposals; developing targeted marine resource proposals in co-funding arrangements with government and industry (complementary project proposal, or CPP); commercial hire of IODP drilling vessels when they are in the region. Three areas were discussed: 


\subsubsection{Petroleum potential of the Lord Howe Rise}

This is the largest submerged continent in the world and there are fundamental questions about its petroleum potential related to the largely unknown history and fabric of the rise. The rise contains a number of deep rift basins, with up to $6000 \mathrm{~m}$ of sediment, that are well characterised by seismic profiling but may or may not contain source, reservoir and cap rocks. Sparse stratigraphic information is limited to early DSDP wells (Legs 21 and 90). Potential exploration targets are believed to be Cretaceous, but only the uppermost Cretaceous (Maastrichtian) was reached in just two holes. Without basic stratigraphic information, the next stage in assessment of petroleum potential cannot be achieved and the preMaastrichtian geohistory cannot be determined.

\subsubsection{Metal resource potential of southwest Pacific island arcs and back-arc basins}

Many of the island nations of the southwest Pacific have limited land area with scarce mineral resources, but do have massive maritime territories with largely unexplored mineral potential. It is estimated that more than one million square kilometres of seafloor in the Asia-Pacific region is under mineral exploration license, providing researchers with an outstanding opportunity to leverage the often high-quality site survey data generated by mineral explorers to draft drilling proposals addressing fundamental scientific questions related to volcanology, crustal fluid fluxes, subduction input of volatiles into the oceans, and the limits and origin of life on Earth.

\subsubsection{8-Pre: Brothers arc flux}

The Brothers volcano has been extensively surveyed from surface vessels and submersibles. However, it lacks deep drilling, which is needed to understand its subseafloor hydrology and potential to form large accumulations of $\mathrm{Cu}-\mathrm{Au}$ mineralisation. Two distinct hydrothermal systems of very different end-member chemical compositions exist within the same area, and drilling provides the opportunity to address scientific questions relevant to microbiology, volcanology, and the formation of significant ore bodies.

\subsubsection{Manus Basin}

The Manus back-arc basin lies at the convergent boundary between the major Indo-Australian and Pacific plates, and exhibits a complex tectonic history, including reversal of subduction due to the arrival of the Ontong Java Plateau at the old subduction zone. There are at least nineteen active sites of hydrothermal activity within the Manus Basin, making the area an ideal natural laboratory to investigate the controls on and inputs into ore forming processes on both a regional and a local scale.
Acknowledgements. Thanks are given to IODP-MI, USSSP, J-DESC, ANZIC and the University of Sydney for their generous support of this Workshop.

Edited by: G. Camoin

Reviewed by: E. Gischler and one anonymous referee

\section{References}

Gurnis, M., Hall, C. E., and Lavier, L. L.: Evolving force balance during incipient subduction, Geochem. Geophy. Geosy., 5, Q07001, doi:10.1029/2003GC000681, 2004.

Ito, Y., Tsuji, T., Osada, Y., Kido, M., Inazu, D., Hayashi, Y., Tsushima, H., Hino, R., and Fujimoto, H.: Frontal wedge deformation near the source region of the 2011 Tohoku-Oki earthquake, Geophys. Res. Lett., 38, L00G05, doi:10.1029/2011GL048355, 2011.

Kodaira, S., No, T., Nakamura, Y., Fujiawara, T., Kaiho, Y., Miura, S., Takahashi, N., Kaneda, Y., and Taira, A.: Coseismic fault rupture at the trench axis during the 2011 Tohoku-oki earthquake, Nat. Geosci., 5, 646-650, doi:10.1038/ngeo1547, 2012.

Maeda, T., Furumura, T., Sakai, S., and Shinohara, M.: Significant tsunami observed at ocean-bottom pressure gauges during the 2011 off the Pacific coast of Tohoku Earthquake, Earth Planets Space, 63, 803-808, 2011.

Sakaguchi, A., Chester, F., Curewitz, D., Fabbri, O., Goldsby, D., Kimura, G., Li, C.-F., Masaki, Y., Screaton, E. J., Tsutsumi, A., Ujiie, K., and Yamaguchi, A.: Seismic slip propagation to the updip end of plate boundary subduction interface faults: Vitrinite reflectance geothermometry on IODP NanTroSEIZE cores, Geology, 39, 395-398, 2011.

Steinberger, B., Sutherland, R., and O'Connell, R. J.: Prediction of Emperor-Hawaii seamount locations from a revised model of global plate motion and mantle flow, Nature, 430, 167-173, 2004.

Taylor, B.: The single largest oceanic plateau: Ontong JavaManihiki-Hikurangi, Earth Planet. Sc. Lett., 241, 372-380, doi:10.1016/j.epsl.2005.11.049, 2006.

Tejada, M. L. G., Suzuki, K., Kuroda, K., Coccioni, R., Mahoney, J. J., Ohkuchi, N., Sakamoto, T., and Tatsumi, Y.: Ontong Java Plateau eruption as a trigger for the early Aptian oceanic anoxic event, Geology, 37, 855-858, 2009.

Wortmann, U. G., Bernasconi, S. M., and Bottcher, M. E.: Hypersulfidic deep biosphere indicates extreme sulfur isotope fractionation during single-step microbial sulfate reduction, Geology, 29, 647-650, 2011.

\section{Related Web Links}

http://www.iodp.org/workshops http://www.earthbyte.org/workshops/SWPacific_IODP/ http://www.iodp.org/Science-Plan-for-2013-2023/ 